\title{
Author Correction: Unconventional valley- dependent optical selection rules and landau level mixing in bilayer graphene
}

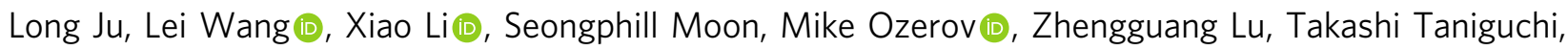
Kenji Watanabe (1), Erich Mueller (B), Fan Zhang (D), Dmitry Smirnov (D), Farhan Rana \& Paul L. McEuen (D)

Correction to: Nature Communications https://doi.org/10.1038/s41467-020-16844-y, published online 10 June 2020.

The original version of this Article contained errors in the Acknowledgements:

F.Z. is supported by ARO under Grant No. W911NF-18-1-0416 and NSF under Grant No. DMR-1921581 (DMREF). This was incorrectly given as F.Z. is supported by the University of Texas at Dallas research enhancement funds.

Funding from the NSF MRSEC program (DMR-1719875) was incorrectly given as Funding from the NSF MRSEC program (DMR1120296).

This has now been corrected in both the PDF and HTML versions of the Article.

Published online: 24 June 2020

(c) Open Access This article is licensed under a Creative Commons Attribution 4.0 International License, which permits use, sharing, adaptation, distribution and reproduction in any medium or format, as long as you give appropriate credit to the original author(s) and the source, provide a link to the Creative Commons license, and indicate if changes were made. The images or other third party material in this article are included in the article's Creative Commons license, unless indicated otherwise in a credit line to the material. If material is not included in the article's Creative Commons license and your intended use is not permitted by statutory regulation or exceeds the permitted use, you will need to obtain permission directly from the copyright holder. To view a copy of this license, visit http://creativecommons.org/licenses/by/4.0/.

(c) The Author(s) 2020 